\title{
Desarrollos urbanos para futuros distópicos: de Metrópolis a Cyberpunk 2077
}

Christian Franco Torre

RESUMEN

El videjuego Cyberpunk 2077, desarrollado por CD Projekt RED, está ambientado en Night City, una megalópolis que el jugador puede recorrer con una libertad inédita, lo que unido a una perspectiva en primera persona propicia una sugestiva experiencia inmersiva. Pero al recorrer Night City, el jugador descubre una ciudad que le resulta familiar, tanto en su diseño urbano y arquitectónico como en la naturaleza de su población, ya que la megalópolis de Cyberpunk 2077 recoge toda una iconografía de la representación de urbes distópicas en distintas disciplinas artísticas que se puede rastrear hasta Metrópolis (Metropolis, Fritz Lang, 1927), y que reflejan tanto las intuiciones de sus creadores sobre cómo serán las ciudades del futuro como sus inquietantes reflexiones sobre la urbanidad de su tiempo.

\section{PALABRAS CLAVE}

Cine, videojuegos, distopías, urbanismo, cyberpunk

Urban developments for dystopian futures: from Metropolis to Cyberpunk 2077

ABSTRACT

The Cyberpunk 2077 video game, developed by CD Projekt RED, is set in Night City, a megalopolis that the player can travel with unprecedented freedom besides with a first-person perspective that provides an evocative immersive experience.

But when touring Night City, the player discovers a city that is familiar to him, both in its urban and architectural design and in the origin of its population, since the megalopolis of Cyberpunk 2077 contains an entire iconography of the representation of dystopian cities in different disciplines artistic that can be traced back to Metropolis (Fritz Lang, 1927), and that reflect both the intuitions of their creators about the cities of the future will be like and their disturbing reflections on the urbanity of their time.

Film, video games, dystopias, urbanism, cyberpunk 
La inmersión en Night City no podía ser más estimulante. La última de las megalópolis es un organismo vivo y complejo, que tiene en todo momento, en cada instante del día y de la noche, un tránsito ingente de personas y vehículos, de transeúntes, policías, netrunners, mercenarios, empleados de las grandes corporaciones que dominan el centro, matones de medio pelo, prostitutas, rateros y sicarios de las bandas que controlan la periferia. Una fauna urbana que dota a la urbe de una idiosincrasia singular. Todo es nuevo en Night City y, sin embargo, todo tiene un sabor añejo, una tendencia al déjà vu.

Night City es el escenario sobre el que se desarrolla el videojuego Cyberpunk 2077, desarrolado por CD Projekt RED y que propone al jugador una aventura inmersiva en una megalópolis localizada en un futuro no muy lejano, ese 2077 al que hace alusión el título, en el que rige un sistema de corte totalitario dominado por grandes corporaciones. Se trata, en esencia, de una obra de naturaleza distópica, pero no a la manera de las obras literarias, ya clásicas, que pusieron los cimientos del género en torno al segundo cuarto del siglo XX -esencialmente Un mundo feliz (Brave New World, Aldous Huxley, 1932), 1984 (George Orwell, 1949) y Fahrenheit 451 (Ray Bradbury, 1953)- sino asumiendo el modelo del cyberpunk, subgénero de la ciencia-ficción que cobra carta de naturaleza en el primer lustro de la década de 1980, pero cuyo imaginario amalgama soluciones y hallazgos de los cómics europeos de la década de 1970 cuyo origen se puede rastrear hasta el filme Metrópolis (Metropolis, Fritz Lang, 1927).

Las diferencias entre la distopía de naturaleza más clásica y la vinculada al cyberpunk son notorias. Aunque ambas se desarrollan preferentemente en entornos urbanos (en oposición a otro tipo de obras distópicas nacidas del temor a un apocalipsis nuclear que reflexionan sobre la destrucción del tejido social y exploran la tierra devastada como escenario) la naturaleza de su discurso es radicalmente distinto, pues la utopía de partida es igualmente muy diferente: mientras en las primeras se trata de desmontar el ideal comunista o totalitario, en las obras cyberpunk el objetivo es mostrar las derivas de un sistema capitalista.

Este cambio resulta crucial, ya que penetra en el alma mismo del discurso. Tal y como explica Núñez Ladeveze, la distopía nace de la puesta en práctica de una utopía. "Si la utopía es un ideal", sostiene el autor, "la distopía es la descripción, deformada por la denuncia, de la práctica de esa idea. Pero el elemento utópico es idéntico en ambas: las ideas que hacen la utopía, al convertirse en hechos, al tratar de sortear la larga aventura que separa las bellas palabras de los actos humanos, generan la distopía".

En las siguientes páginas, se esbozará la evolución de esta tipología urbana de ficción, desgranando sus cualidades comunes y reseñando los hitos fundamentales en su evolución, poniendo especial énfasis en la progresiva construcción de una estética propia que emerge en plenitud con la aparición del cyberpunk. Como último hito de esta evolución, se situará precisamente Cyberpunk 2077, una obra que recoge y sintetiza todo este legado iconográfico, revelándose en cierta manera como un pastiche interactivo, pero siendo al mismo tiempo fiel heredero de esta tradición en su pretensión de construir un reflejo voluptuoso, siniestro y deshumanizado de las urbes del presente.

\section{La ciudad de Moebius}

El desarrollo de la iconografía vinculada a la megalópolis distópica encontrará en el cine su medio preferente de configuración, pero no el único. Entre la citada Metrópolis de Lang y Blade Runner (Ridley Scott, 1982), que marcará un nuevo paradigma para estas tipologías urbanas de ficción, se desarrolla toda una corriente, dentro del cómic europeo, que anticipa la eclosión del cyberpunk y que tendrá además una influencia crucial en el diseño de Ridley Scott y Syd Mead para ese Los Ángeles de 2019 que sirve de escenario a Blade Runner. El origen de esta tendencia se sitúa en los cómics publicados en la revista francesa Métal Hurlant, especialmente en la obra de Jean Giraud, "Moebius", cocreador de la publicación y miembro destacado de la agrupación de historietistas Les Humanoïdes Associés (Humanoides asociados). ${ }^{2}$

Un título en concreto dará a Scott y Mead el tono y la atmósfera de Blade Runner: The Long Tomorrow, una historieta de apenas 16 páginas

NÚÑEZ LADEVECE, Luis, "De la utopía clásica a la distopía actual”, Revista de Estudios Politicos n. ${ }^{\circ} 44$ (nueva época), Madrid, Centro de Estudios Políticos y Constitucionales, Marzo-Abril 1985, p. 51.

2 Sobre la influencia de este grupo de dibujantes y de la revista Métal Hurlant, véase COMA, Javier, El ocaso de los héroes en los cómics de autor, Península, Barcelona, 1984, pp. 140-148. 
y con guion de Dan 0'Bannon, en la que se anticipan las principales claves del filme: la inclusión de las formas del film noir de inspiración chandleriana en una historia de ciencia-ficción, la reflexión sobre la humanidad de formas de vida cibernéticas, y por supuesto el diseño de esa ciudad mestiza y marcada a fuego por las desigualdades sociales, atestada y agonizante, pero al mismo tiempo fascinante. ${ }^{3}$ [Figura 1]

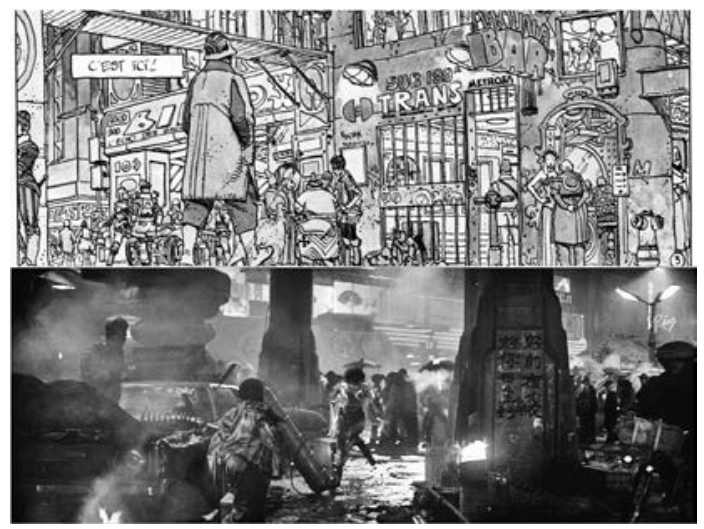

Fig. 1. Arriba, una viñeta de The Long Tomorrow; abajo, un fotograma de Blade Runner.

El alcance de The Long Tomorrow, publicado originalmente en 1976, impregna buena parte de las recreaciones de ciudades futuristas en el cine posterior, amplificado de manera crucial por la condición de Blade Runner de paradigma estético. En las viñetas de Moebius ya se perciben elementos como unos coches voladores que profundizan en la congestión del tráfico, la colisión entre unos desarrollos urbanos pretendidamente utópicos que conviven con suburbios deprimidos o la presencia ubicua de una publicidad invasiva, indiciaria del triunfo absoluto del capitalismo salvaje.

Moebius, de hecho, era consciente de que, al crear un entorno arquitectónico, era tan importante diseñar la ciudad, sus calles y sus edificios, como integrar otros vehículos, elementos

\footnotetext{
DA PAIXÃO Jr., Márcio Mário, "Os quadrinhos cinematográficos de Moebius”, Actas del XXVI Congresso Anual em Ciència da Comunicação, Belo Horizonte/MG, 2 a 6 de septiembre de 2003 [versión online: http://www.portcom.intercom.org.br/pdfs/4071058669 7698889077377550716712502988.pdf, última consulta: 12-diciembre-2020]; MOLINA-SILES, Pedro y BARROS COSTA, Hugo, “Blade Runner: Los Ángeles 2019. Los dibujos de una ciudad en decadencia”, Expresión Gráfica Arquitectónica n³6, Universitat Politècnica de València, 2019, pp. 186-197.
}

muebles y accesorios coherentes con ese futuro probable. De ahí que sus ciudades, antes que ser realistas en lo arquitectónico, alcancen una profundidad mayor gracias a todos esos elementos que la van integrando, como el propio autor insinuaba en una entrevista con Patricia Zanotti, publicada en 1983:

Cuando haces cómics, estás obligado a jugar al arquitecto. En ciencia ficción, sobre todo, no solo debemos inventar arquitecturas probables, sino también crear armas, naves espaciales, tecnologías, morfologías. Pero los problemas reales de la arquitectura son demasiado complejos. ¡Tiro la toalla! ${ }^{4}$

El dibujante francés profundizaría en su visión urbana en otras dos obras clave: la serie El garaje hermético (Le Garage Hermetique, publicada entre 1976 y 1979) y especialmente en El Incal (L'Incal/Les aventures de John Difool), una saga con guion de Alejandro Jodorowski publicada en seis entregas entre 1980 y 1988. Para este cómic, Moebius diseña una ciudad que se desarrolla en altura, con infinidad de niveles que remarcan una estructura social jerarquizada. El inicio de la saga no podía ser más explícito: en las primeras viñetas, el protagonista, John Difool, es arrojado por un grupo de matones a un interminable atrio desde Suicide Square. Un entramado urbano en cuya concepción parece evidente que Moebius pudo inspirarse en el desarrollo en terrazas del Mériadeck, en Burdeos, un experimento urbanístico que se fraguó durante la década anterior. ${ }^{5}$

Los desarrollos urbanísticos de Moebius para The Long Tomorrow y El Incal tuvieron una traslación directa en El quinto elemento (Le Cinquième Élément, Luc Besson, 1997), superproducción europea cuya trama arranca en

\footnotetext{
Declaraciones de Moebius en ZANOTTI, Patrizia, Jean Moebius Giraud, colección L'autore e il fumetto vol. 7, Editori del Grifo, Montepulciano (Siena), 1983, p. 17. La cita original, en italiano, es como sigue: "Quando si fanno dei comics si è obbligati a giocare all'architetto. Nella fantascienza, sopratutto, non solo bisogna inventare delle architetture probabili, ma anche creare armi, astronavi, tecnologie, morfologie. Ma i problemi reali dell'architettura sono veramente troppo complessi. Getto la spugna!".

5 Sobre esta experiencia arquitectónica, véase BOUSSARIE, "L'urbanisme moderne de dalle, histoire d'une utopie inachevée: le cas de Mériadeck", Sciences de l'Homme et Société, 2014 [Versión online: https://core. ac.uk/download/pdf/51944340.pdf, última consulta: 13-diciembre-2020].
} 
una Nueva York del siglo XXIII en cuyo diseño participó directamente el dibujante galo, en colaboración con otro icono del cómic europeo como es Jean-Claude Mézières, el creador de Valérian. ${ }^{6}$ En esta ciudad multicultural y atestada, de rascacielos hipertrofiados, el tráfico rodado se efectúa de manera definitiva con vehículos voladores, ya que los niveles más bajos, la planta a pie de calle y los pisos que se sitúan inmediatamente por encima, son completamente impracticables, anegados por una perpetua contaminación.

\section{El nacimiento del cyberpunk}

Para cuando se estrenó El quinto elemento, la iconografía de la megalópolis ya estaba plenamente consolidada. De hecho, hay un momento de especial efervescencia, entre 1981 y 1984, en el que una sucesión de obras de ficción, desarrolladas en diferentes medios y formatos, alimenta y estructura a una iconografía en franca expansión. Por supuesto, entre esas obras cruciales están las citadas El Incal (cuyo primer volumen, L'Incal Noir, vio la luz en 1981, y los dos siguientes, L'Incal Lumière y Ce qui est en bas, en 1982 y 1984 respectivamente) y Blade Runner, pero también otras que incorporan hallazgos y matices fundamentales en la iconografía de las megalópolis distópicas como el arco Block Mania del cómic británico Juez Dredd (Judge Dredd), publicado en el otoño de 1981; la saga de manga Akira (アキラ), de Katsuhiro Otomo (que empezó a publicarse precisamente en 1982); la novela Neuromante (Neuromancer), de William Gibson, que vio la luz en 1984; y la versión de Metrópolis coloreada y con música pop contemporánea, editada por Giorgio Moroder.

El caso de Juez Dredd es particular. Su nacimiento se sitúa en 1977, en el marco de la irrupción de la revista británica $2000 \mathrm{AD}$, publicación de periodicidad semanal creada por Pat Mills, que seguía la estela y el modelo de Métal Hurlant. Entre Mills, el guionista John Wagner y el dibujante Carlos Ezquerra dise-

\footnotetext{
Mézières actuó como diseñador no acreditado en la película de Besson, aunque su trabajo fue reconocido posteriormente y su nombre figura en archivos como la web especializada Internet Movie Database (IMDB). La ficha online del filme se puede consultar en: https:// www.imdb.com/title/tt0119116/?ref_=nm_flmg_ardp_2 [última consulta: 13-diciembre-2020].
}

ñaron al Juez Dredd, un expeditivo agente de la ley, con atribuciones de juez, jurado y verdugo, que imparte justicia en la megalópolis de Mega-City Uno, en el año 2099. Desde su primera aparición, en el número 2 de la revista (que vio la luz el 5 de marzo de 1977), el Juez Dredd adquirió gran popularidad y se convirtió en la figura central de la publicación, lo que propició un tratamiento preferente para el personaje, que se tradujo en una mayor disponibilidad de espacio en la revista que otras historias y en el desarrollo de arcos narrativos que se extendían varios números, además de destinar a sus cómics a los mejores talentos de la editorial. ${ }^{7}$

En los primeros años, el desarrollo urbano de Mega-City Uno no tenía una personalidad propia, aunque ya se percibían patrones marcadamente influenciados por Moebius, con varios niveles de edificaciones e improbables trazados de autopista circunvalando la urbe, para permitir a los jueces recorrerla con sus motocicletas. ${ }^{8}$ La verdadera naturaleza de Mega-City Uno va tomando forma progresivamente, gracias a las sucesivas aportaciones de guionistas y dibujantes. Pero será en el arco Block Mania, publicado en nueve entregas entre el 31 de octubre y el 26 de diciembre de 1981, cuando se muestre ya una Mega-City Uno dividida en descomunales

Además de Wagner y Ezquerra, Dredd pasó por las manos de guionistas como Kelvin Gosnell, Pat Mills, Alan Grant o el mismísimo Alan Moore (cuya entrada en $2000 A D$ se produjo precisamente a raíz de una historia del juez), y de dibujantes como Mike McMahon, Ian Gibson, John Cooper o Brian Bolland.

8 De hecho, en sus primeros años el protagonismo de Mega-City Uno se vería diluido con las sucesivas incursiones de Dredd en otros territorios, principalmente Luna-1 (una colonia en el satélite terrestre) y la denominada "Tierra maldita" ("Cursed Earth"), un páramo que circunda las megalópolis, arrasado por una guerra nuclear. En lo relativo a la Tierra Maldita profundiza en otra iconografía distópica, como es la del Páramo o el Yermo ("Wasteland"), un entorno arrasado por un cataclismo o una guerra nuclear que se revela como escenario principal en obras como la saga Mad Max. Por otro lado, cabe reseñar que en las primeras apariciones de Dredd ni siquiera se habla de Mega-City Uno, sino que se sitúa directamente al personaje en la Nueva York de 2099. Tal y como se indica en la primera historia del personaje, se trata de una ciudad "Donde gigantescos rascacielos se elevan kilómetros en el aire. Pequeños edificios como el Empire State están en ruinas... iConvertidos en escondites para depravados criminales!”. Para este análisis, se ha utilizado la edición de las obras completas del personaje, titulada El Juez Dredd. Los archivos completos y publicada en España por la editorial Kraken, en varios tomos, a partir de 2014. 
bloques de viviendas, desarrollados en altura y en los que pueden vivir del orden de 75.000 personas, y conectadas por grandes autopistas. Marcada por una profunda desigualdad y con unos índices de criminalidad disparados, la megalópolis está separada de su desolado entorno por una imponente muralla, y los jueces no se encargan solo de mantener el orden, sino que ostentan también el poder ejecutivo en la urbe. Un auténtico estado policial. ${ }^{9}$

Mientras Moebius y el Juez Dredd marcaban la pauta de los desarrollos urbanos distópicos en el cómic europeo, en Japón emergía la figura de Katsuhiro Otomo, creador del manga Akira. ${ }^{10}$ La serie se localiza en Neo-Tokio, una megalópolis surgida de las cenizas del Tokio contemporáneo, en 2019. En el manga, la capital japonesa habría sido arrasada en 1988, a causa de una misteriosa explosión que, a su vez, marcó el inicio de una guerra nuclear. Junto a un gigantesco cráter, vestigio del cataclismo, emergió una megalópolis que, tres décadas después, bulle al borde de una revolución. La urbe, en la que las estructuras en terrazas co-

El Juez Dredd ha disfrutado, hasta la fecha, de dos adaptaciones cinematográficas. La primera, Juez Dre$d d$ (Judge Dredd, Danny Cannon, 1995) es una película que responde a los cánones del actioner finisecular, protagonizada por uno de sus máximos representantes, Sylvester Stallone, y que desarrolla uno de los arcos narrativos más relevantes del cómic original: el del Juez Rico. El diseño de Mega-City Uno adolece de cierto barroquismo, y parte del metraje se desarrolla en la "Tierra Maldita". Coincidiendo con el estreno, se lanzó un videojuego homónimo, desarrollado por Probe Software, que fusionaba el género de plataformas con el shoot-em-up, muy en la línea de otros productos arcade de la época. En 2012, se estrenó una nueva película sobre el personaje, Dredd (Pete Travis, 2012), más fiel al espíritu de los cómics y con una visión de Mega-City Uno menos estilizada. El filme debía ser el inicio de una trilogía e incluso se estudió la posibilidad de realizar una serie de televisión, pero sus discretos resultados en taquilla frenaron ambas opciones. En pocos años, Dredd ha alcanzado una categoría próxima a la de "película de culto", por lo que periódicamente surgen rumores e informaciones acerca de la posibilidad de que sus responsables, Pete Travis y el guionista Alex Garland, y su protagonista, Karl Urban, se reúnan para una nueva incursión en el mundo de Dredd.

10 Conviene mencionar también una serie de cómics que, si bien no tuvo la resonancia ni gozó del éxito popular de las otras citadas, sí que resulta estimulante y ha tenido cierta influencia posterior: se trata de Las ciudades oscuras (Les Cités obscures), obra del dibujante François Schuiten y el guionista Benoît Peeters, iniciada en 1983 con el álbum Las murallas de Samaris (Les murailles de Samaris) y que en la actualidad acumula una docena de títulos (el último publicado en 2018). nectan descomunales rascacielos, está atravesada por grandes autopistas en las que Kaneda y sus compañeros, "The Capsules", combaten contra otras bandas de motoristas.

De nuevo, la influencia de Moebius en la obra de Otomo resulta evidente, pero además el autor japonés reivindica el legado de Metrópolis hasta tal punto que, en la versión animada del manga, que él mismo dirige en 1988, incluye una vista análoga a la de la megalópolis de Lang en los primeros compases del filme, asimilando el skyline de Neo-Tokio al del filme alemán. [Figura 2]

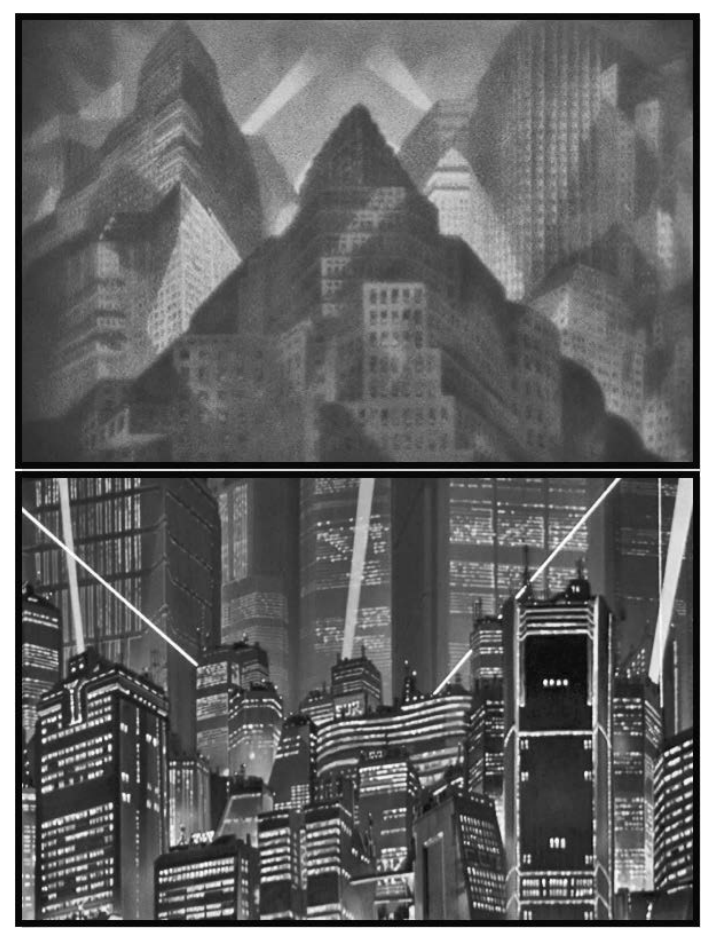

Fig. 2. Arriba, un fotograma de Metrópolis; abajo, fotograma de la versión anime de Akira.

La influencia de la película de Lang seguía, pues, vigente, como se percibe por su impacto en Blade Runner y en Akira. Pero este legado se vería reforzado con el estreno, en 1984, de la versión restaurada por Giorgio Moroder, con imágenes coloreadas y música de artistas contemporáneos, como Bonnie Tyler, Adam Ant o Freddie Mercury. ${ }^{11}$ La versión de Moro-

11 La fascinación de Mercury con el filme llegó al punto de que incluyó secuencias de la película y un homenaje en el videoclip de Radio $G a-G a$, estrenado asimismo en 1984. Sobre la versión de Metrópolis de Giorgio Moroder y su influencia, véase ELSAESSER, Thomas, 
der permitió a nuevas generaciones de espectadores descubrir la obra de Lang, y amplificó su influencia entre los creadores de diferentes ámbitos.

Ese mismo año, se produjo el lanzamiento de la novela Neuromante, de William Gibson. Ambientada en un futuro marcado por la penetración absoluta de la tecnología (hasta el punto de que proliferan los implantes biónicos), esta obra dio carta de naturaleza al subgénero cyberpunk y, de paso, incorporó los últimos matices en la configuración definitiva de la iconografía de la megalópolis distópica.

\section{Claves de una iconografía}

La consolidación del cyberpunk será decisiva en la construcción de la imagen de esas ciudades del futuro. De hecho, una y otra van de la mano, se desarrollan en paralelo, toda vez que la megalópolis distópica será el escenario natural de esas narrativas. Pero su naturaleza, como se ha visto, desborda los márgenes del subgénero, hasta el punto de desarrollar una iconografía propia que los autores cyberpunk asumen, enriqueciéndola pero respetando su claves fundamentales.

En su diseño urbano, estas urbes destacan por su condición amalgamada. Ya en la Metrópolis langiana se aprecia una mezcolanza entre los diseños teóricos del futurista Antonio Sant'Elia con soluciones próximas al art decó y una deriva expresionista filtrada por autores como Hans Poelzig. ${ }^{12}$ A esas influencias se incorporarán, en ulteriores megalópolis, las experiencias del movimiento moderno, especialmente Le Corbussier. Pero serán asimilaciones distorsionadas, en las que los hallazgos de la unidad de habitación se pervierten en bloques oscuros, deteriorados, insalubres y saturados, replicando las peores mutaciones arquitectónicas de las banlieues.

La megalópolis distópica, no obstante, dista de ser uniforme. De hecho, una de sus cualidades fundamentales es su condición heterogé-

Metropolis, Bristish Film Institute, Londres, 2000, pp. $37-41$.

12 SANTOS, Antonio, Tierras de ningún lugar. Distopia y cine, Cátedra, Madrid, 2019, edición digital, posición 494-545; ELSAESSER, Thomas, Metropolis, opus cit., pp. $17-30$ nea. ${ }^{13}$ Atravesada por una brutal desigualdad, el skyline de la ciudad estará marcado por los brillantes rascacielos de sus distritos centrales, en los que residen las clases acomodadas. La arquitectura brutalista emergerá de forma puntual, principalmente para distinguir los centros de poder, pero el eclecticismo será dominante en cualquier caso y, a medida que nos alejamos de los distritos más pudientes, trazado y alzado perderán lustre: las avenidas se tornarán callejuelas inextricables, y los edificios, aunque puedan mantener sus monumentales dimensiones, carecerán de toda brillantez.

El desarrollo urbano está condicionado por la verticalidad. Los grandes bloques arquitectónicos estarán conectados a través de puentes, pasadizos elevados y estructuras aterrazadas. La eventual proliferación de vehículos aéreos determinará posibles accesos directos a las viviendas, como sucede en la Nueva York de $E l$ quinto elemento, donde de hecho la superficie es intransitable debido a la contaminación.

La comunicación es crucial para articular la megalópolis. En el caso de que los vehículos aéreos no sean dominantes, proliferarán las vías rápidas y las autopistas, formando en ocasiones extravagantes estructuras, como sucede en el Neo-Tokio de Akira o en los cómics del Juez Dredd. La inclusión de vehículos autónomos no variará esta cualidad, como se aprecia en Minority Report (Steven Spielberg, 2002), en la que las cápsulas con piloto automático conectan viviendas y empleos a través de atestadas autovías con tráfico armónico.

El mestizaje será otra constante de la megalópolis distópica. Es algo que se aprecia tanto en su sociología como en la propia configuración urbana, con esa amalgama de estilos arquitectónicos que se solapan en los barrios más marginales. Es frecuente la colusión entre la cultura oriental, principalmente la japonesa, y la anglosajona, en detrimento de otras minorías que, no obstante, han ido adquiriendo peso en sucesivas revisiones de esta iconografía, caso de los chinos, los eslavos y los latinos. Este mestizaje, en todo caso, aflora también en los

\footnotetext{
SANTOS, Antonio, Tierras de ningún lugar. Distopia $y$ cine, opus cit., pos. 617. A propósito de Metrópolis, el autor señala, a nuestro juicio con acierto, que: "La amalgama de géneros y estilos que luce la película anticipa el fenómeno posmoderno en su condición de ciudad pastiche y escindida, una situación que explotará literalmente, y de forma autoconsciente, la posterior Blade Runner".
} 
mecanismos de comunicación, con el florecimiento de jergas, de "neolenguas", que a su vez entran en conflicto con el lenguaje más depurado que se emplea en los ámbitos más selectos de la pirámide social.

Todas estas ciudades se definen además por tener una condición dual. Se trata de una herencia decisiva de Metrópolis, que supone la aplicación de la temática del döppelhanger, el doble siniestro, no solo a determinados personajes del filme (como es el caso de María y el robot, pero también del dúo formado por Freder y Rotwang), sino también a la propia ciudad, una urbe escindida en dos, en cuyas entrañas se esconde una ciudad oscura, envés de la luminosa megalópolis que florece en la superficie. ${ }^{14}$ Esta cualidad dual de Metrópolis recoge una tradición arraigada en el cine expresionista, como es la de las ciudades subterráneas, pero a la vez arroja su propia conclusión: la de una utopía deformada, engañosa, que se asienta sobre los doloridos hombros de una parte cuantiosa de sus ciudadanos, una realidad que el resto de los habitantes, los privilegiados, ignoran.

El desarrollo de esa dualidad puede ser físico o virtual. En Demolition Man (Marco Brambilla, 1993), una película que se puede interpretar como una fusión de Metrópolis con Un mundo feliz en el marco del cine de acción finisecular, la ciudad de San Ángeles, -megalópolis surgida de la fusión de Los Ángeles, Santa Bárbara y San Diego, en la que todo tipo de violencia ha sido prohibido (como también el contacto carnal)-, esconde bajo su superficie, en el sub-

14 SÁNCHEZ-BIOSCA, Vicente, Sombras de Weimar: contribución a la historia del cine alemán, 1918-1933, opus cit., pp. 348-353; KRACAUER, Siegfried, De Caligari a Hitler. Una historia psicológica del cine alemán, Paidós, Barcelona, 1985, pp. 142-144 [1 1ª edición: From Caligary to Hitler. A Psychological History of the German Film, Princeton University Press, 1947]; SAN MIGUEL MONTES, Alfonso, "La torre de los siete jorobados: cuando el Madrid castizo abrió una puerta a un modelo urbano expresionista", Biblioteca Virtual Miguel de Cervantes, Alicante, 2010 [edición digital: http://www.cervantesvirtual.com/obra-visor/la-torre-de-los-siete-jorobados-cuando-el-madrid-castizo-abrio-una-puerta-a-un-modelo-urbano-expresionista/html/b3ba7107-9f51-43c2-b9bc-7656a28d8642. html, última consulta: 12-diciembre-2020]. Aunque no está dedicado expresamente a Metrópolis o al expresionismo alemán, el texto de San Miguel resulta revelador al analizar, a través de las herencias del cine de Weimar en La torre de los siete jorobados (Edgar Neville, 1944), las claves de ese modelo urbano de raíz expresionista y marcado por la dualidad, además de su evolución en el cine alemán de entreguerras. suelo, a toda una comunidad de desheredados, de ciudadanos expulsados de la ciudad exterior, cuya miserable pero honesta existencia desmiente la utópica fachada del exterior.

La introducción del ciberespacio, especialmente desde la publicación de Neuromante (donde ya se utiliza el término "matriz" para denominar al espacio virtual) propiciará nuevas variaciones temáticas sobre esa cualidad doble, en las que la urbe física convivirá, se solapará o incluso colisionará con esa otra ciudad digital. Esta variante será explotada en filmes como Dark City (Alex Proyas, 1998), Ready Player One (Steven Spielberg, 2018), y en el manga Ghost in the Shell, de Masamune Shirow, que daria lugar a dos animes de gran influencia, ambos dirigidos por Mamoru Oshii: Ghost in the Shell (1995) y Ghost in the Shell 2: Innocence (2004). Y con matices, esta condición dual también emergerá en la crucial película Días extraños (Strange Days, Kathryn Bigelow, 1995), ambientada en un futuro próximo (el año 2000, cinco después del estreno del filme) en el que se pueden grabar los recuerdos (y las sensaciones asociadas a ellos) a través de un dispositivo, lo que de facto propicia una realidad alternativa que influye decisivamente en las vidas de los personajes $\mathrm{y}$, en última instancia, en el destino mismo de la ciudad.

Ambas versiones de esta dualidad, de hecho, no serán excluyentes, como se puede apreciar en Matrix (The Matrix, Andy y Larry Wachowski, 1999). Revisión de Metrópolis enmascarada bajo la influencia del cyberpunk, tanto la película original como sus dos secuelas, Matrix Reloaded y Matrix Revolutions, estrenadas en 2003, pivotan sobre una idea central: los humanos han sido sometidos por las máquinas, que los "cultivan" para usarlos como suministros de energía en un mundo devastado, mientras los mantienen enchufados a una simulación, basada en una gran ciudad del siglo XX, para evitar una revuelta. Solo un pequeño grupo de humanos se opone al dominio de las máquinas desde su base de Sion, de nuevo una ciudad subterránea cuya existencia revela la auténtica naturaleza de la Utopía fallida del exterior. ${ }^{15}$

\footnotetext{
15 La influencia de Metrópolis en Matrix no termina ahí: la reflexión sobre el döppelhanger, convertido aquí en avatar, es constante en la saga de los Wachowski, y el propio personaje de Neo (Keanu Reeves), el elegido que está llamado a liberar a los humanos del yugo de las máquinas, no deja de ser un trasunto de Freder (Gustav
} 
Otra cualidad común a todas las megalópolis distópicas es la presencia asfixiante de una publicidad altamente invasiva. La monstruosa pantalla anunciadora de Coca-Cola que domina uno de los primeros planos de Blade Runner supone la evolución de un planteamiento que ya se percibía en los cómics de Moebius, pródigos en neones y carteles. En posteriores variaciones, la publicidad será aún más agresiva... y peligrosa. En Minority Report, los sensores que identifican a los ciudadanos por el iris de sus ojos, en principio para arrojarles publicidad personalizada, servirán finalmente para cercar al protagonista, convertidas en una eficaz herramienta de control social. Por su parte, en la California de Blade Runner 2049 (Denis Villeneuve, 2017) sensuales mujeres de 50 pies seducen a los viandantes, a los que de nuevo identifican. En esta línea, la hipersexualización de la publicidad también será constante, llegando al paroxismo en la Rogue City de A. I. Inteligencia Artificial (A. I. Artificial Intelligence, Steven Spielberg, 2001), en la que las entradas a la urbe se realizan por túneles cuyos accesos simulan ser bocas de mujeres. De hecho, la propia versión arrasada de Las Vegas de la película de Villeneuve recoge el testigo del filme de Spielberg, con su entrada señalada por descomunales estatuas de mujeres desnudas, como si fuera una versión postapocalíptica de la misma ciudad. [Figura 3]

El diálogo entre California y Las Vegas en Blade Runner 2049 incide también en una clave cuya exploración es desigual, como es la de los límites de la megalópolis distópica. La dicotomía entre la urbe y un yermo circundante, que se presenta en el filme de Villeneuve, conecta esta versión de California con Mega-City Uno, separada por gruesas murallas de la "Tierra maldita" en la que los jueces harán eventuales incursiones. Pero en otras ocasiones, fuera de la ciudad hay una posibilidad de redención. Así sucede en el primer Blade Runner, al menos en la versión estrenada en 1982, en la que Deckard y Rachael logran ver al fin un amanecer en una tierra fértil fuera de Los Ángeles. Y los mismo sucede en Minority Report, en la que los tres "precogs", los videntes que sustentan la unidad de Precrimen, acaban encontrando un remanso de paz más allá

Frölich), el mediador entre la clase dominante y los obreros en el filme de Lang. de los límites de Washington D. C. Del mismo modo, el protagonista de Brazil (Terry Gilliam, 1985) ansía escapar de esa ciudad opresiva y anegada por la burocracia, aunque solo encontrará una salida a través de la demencia. ${ }^{16}$ Porque estas urbes son, por su propia naturaleza, inhóspitas, pese a que su apariencia pueda sugerir otra cosa.

La actuación policial preventiva en la película de Spielberg avanza otra clave de las megalópolis distópicas, como es la limitación de los derechos civiles, generalmente en aras de una mayor seguridad. La violencia atraviesa la vida en la ciudad, lo que determina, en ocasiones, respuestas policiales radicales y, en última instancia, la sustitución de la democracia por sistemas de gobierno autocráticos. La propia actuación policial preventiva de Minority Report o el gobierno de los jueces en Mega-City Uno inciden en esta deriva, aunque en algunos casos, como sucede en el citado arco narrativo Block Mania de Juez Dredd o en Días extraños, la ciudad está al borde de un estallido social, de una revolución.

Pero en la mayor parte de la ocasiones, ese gobierno autocrático no toma la forma de un estado policial, sino que está determinado por el monopolio de una empresa, o en todo caso por el oligopolio de grandes corporaciones que acaban invadiendo los diferentes espacios de poder, como sucede en la obra de William Gibson. En la San Ángeles de Demolition Man, todos los restaurantes son Pizza Hut ya que, como se precisa, fue la única cadena que sobrevivió a una guerra de franquicias. Pero esa alusión no pasa de ser material para un gag, algo muy diferente a la dimensión amenazante que adquieren los anuncios de esas corporaciones en Blade Runner y Blade Runner 2049, o en el escenario que presenta RoboCop (Paul Verhoeven, 1987), en la que una corporación, OCP, adquiere toda una gran ciudad, Detroit, que está al borde del colapso financiero. Es la definitiva conversión del "ciudadano" de Juez Dredd en "cliente", aunque unos y otros siguen sometidos a un estado policial.

\footnotetext{
El final de Brazil será, de hecho, replicado en Repo Men (Miguel Sapochnik, 2010), centrada en los operarios de una empresa que se dedica a proporcionar órganos sanos a sus clientes, acudiendo a expeditivas extracciones de esos mismos órganos en el caso de que no puedan pagar las cuotas.
} 


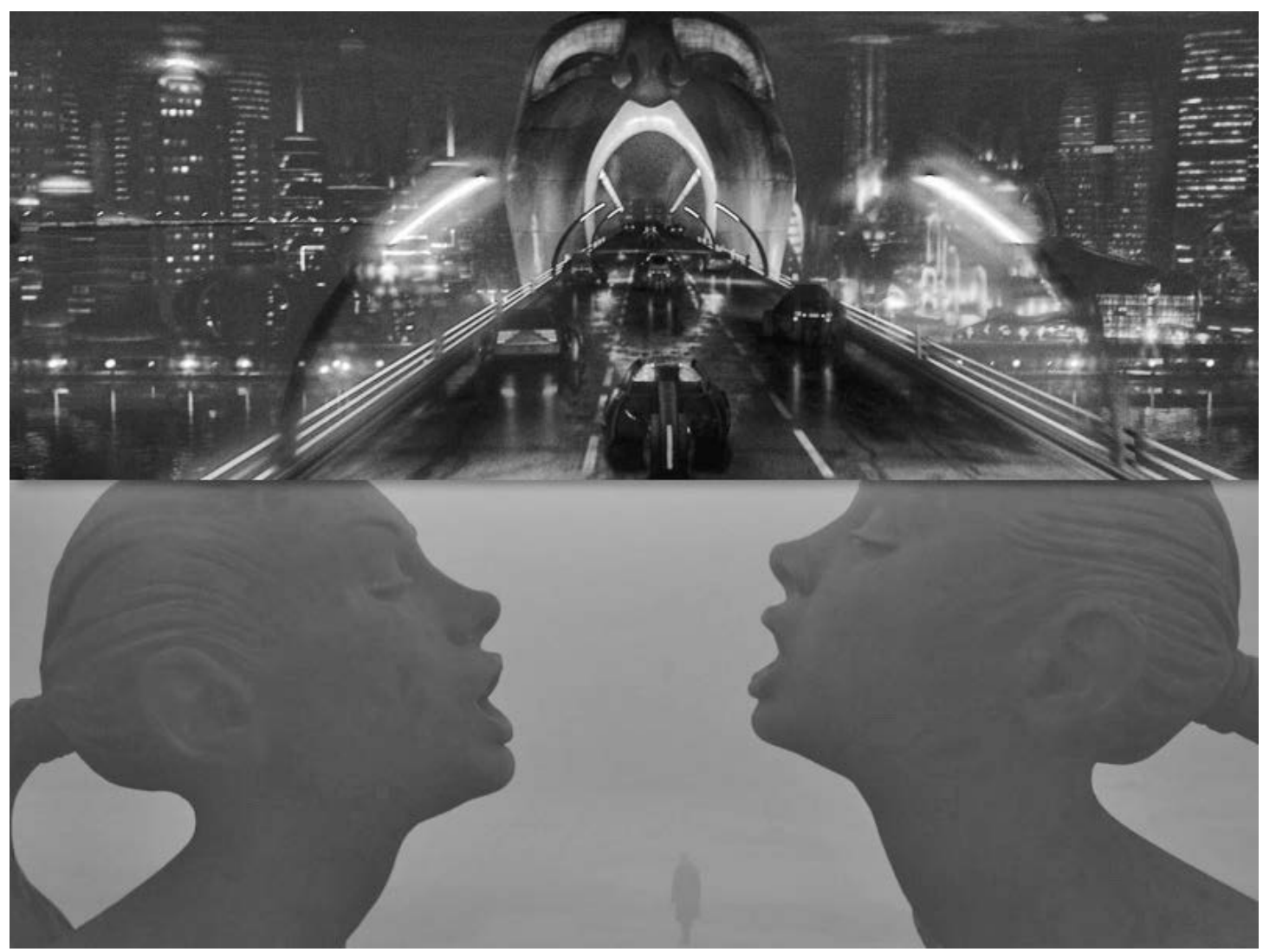

Fig. 3. Arriba, un fotograma de A. I. Inteligencia Artificial; abajo, un fotograma de Blade Runner 2049.

\section{Vivir y morir en Night City}

El mundo de los videojuegos no ha sido ajeno a la construcción de entornos distópicos, cada vez más elaborados y complejos. En 1993, Bullfrog Productions lanzó su influyente Syndicate, un videojuego de estrategia en tiempo real y entornos urbanos ambientado en un futuro en el que diversas corporaciones luchan por el poder mundial. En aquel título y su secuela (Syndicate Wars, lanzado en 1996), el jugador debía dirigir las acciones de una de las corporaciones en liza, tanto a nivel de decisión de qué territorios atacar como sobre el terreno, mandando cuadrillas de soldados mejorados con implantes cibernéticos. Un cuarto de siglo después, la perspectiva isométrica de los Syndicate mutará en un desarrollo en primera persona para recorrer la ciudad sumergida de Rapture, el entorno urbano retrofuturista en el que se ambientan Bioshock (desarrollado por Irrational Games y publicado en 2007) y sus secuelas. Y es que, al igual que sucede en el cine con el desarrollo de las técnicas digitales de efectos especiales, el progresivo incremento del poder de computación permite a los desarrolladores de videojuegos plantear escenarios cada vez más complejos y realistas. En el cine, la eclosión de las imágenes generadas por computador (o CGI, en sus siglas en inglés) permite desarrollar paisajes de síntesis de un gran barroquismo y minuciosidad a un coste asumible y con un resultado muy efectivo. ${ }^{17}$ En cuanto al videojuego, el arraigo de la fantasía y la ciencia-ficción dentro del medio propiciará asimismo la proliferación de productos ambientados en futuros distópicos, fértiles en posibilidades narrativas y que, tal y como apuntan Craig Johnson y Rowan Tulloch, resultan muy apropiados para proponer un desarrollo de personajes

17 Sobre el desarrollo de estos paisajes digitales en el ámbito cinematográfico, especialmente en el cine de Hollywood de finales del siglo XX y los primeros años del XXI, véase LÓPEZ SILVESTRE, Federico, El paisaje virtual. El cine de Hollywood y el neobarroco digital, Madrid, Biblioteca Nueva, 2004. 
conectado al "viaje del héroe" teorizado por Joseph Campbell. ${ }^{18}$

A la hora de ambientar estos futuros distópicos, Johnson y Tulloch destacan dos escenarios: la "Total City", un entorno urbano de grandes dimensiones y poblado de rascacielos, como es el caso de la ciudad de Mirror's Edge (2008); y la "Post-City", enclaves construidos sobre las ruinas de ciudades arrasadas por un algún desastre, como son los escenarios de la saga Fallout. Pero unas y otras no son, sugieren los autores, más que reflejos bifurcados de la ansiedad de la sociedad contemporánea ante la ascensión del "no-lugar", espacios intercambiables que llevan al ser humano a una suerte de anonimato, de uniformidad impuesta, que había teorizado Marc Augé. ${ }^{19}$

Todo este legado que ha ido consolidando la iconografía de la megalópolis distópica confluye en Night City, la ciudad en la que se ambienta Cyberpunk 2077, ambicioso videojuego bisagra entre la octava generación de consolas, la dominada por Xbox One y PlayStation 4, y la novena, la encabezada por Xbox Series y PlayStation 5, que amaneció pocas fechas antes del lanzamiento del producto desarrollado por el estudio polaco CD Projekt RED. Una producción "triple A", usando la jerga propia de la industria del videojuego para referirse a los desarrollos de mayor presupuesto, que de no haberse producido un postrero retraso en su ejecución habría salido a la venta, sintomáticamente, el mismo día que las consolas de la nueva generación. ${ }^{20}$

Más allá de los numerosos bugs que lastraron su puesta de largo, Cyberpunk 2077 resulta una producción más que estimable. ${ }^{21}$ Es una de

18 JOHNSON, Craig, y TULLOCH, Rowan, "Videogames and dystopia: total cities, post-cities and the political unconscious", Journal of Gaming \& Virtual Worlds, vol. 9, n. ${ }^{\circ}$ 3, 1 de septiembre de 2017, pp. 243-256.

19 Ibidem

20 KIM, Matt T. M., "Cyberpunk 2077 Re-confirms December Release Date After Delay Rumors", IGN, 10 de noviembre de 2020. Versión online: https://www. ign.com/articles/cyberpunk-2077-re-confirms-december-release-date-after-delay-rumors [última consulta: 10-diciembre-2020]

21 En su lanzamiento, el videojuego registró importantes errores de programación en sus versiones para consolas, lo que generó una polémica de alcance global. La empresa desarrolladora, CD Projekt RED, incluso fue acusada de ocultar información a los jugadores, toda vez que solo puso a disposición de las revistas especializadas la versión en PC del juego, que no presenta los problemas de rendimiento registrados tanto en PlayS- esas obras que, periódicamente, interpelan a los investigadores sobre la posibilidad de hallar cualidades artísticas en desarrollos vinculados a los mass media. Una barrera que otras disciplinas, como el cine o el cómic, derrumbaron hace décadas, pero que en el caso de los videojuegos aún se afronta con cierta timidez, aunque con un interés creciente.

Este ámbito provee al usuario de una posibilidad de inmersión inédita, incluso de interactuar y modificar ese mundo virtual en el que se desarrolla el videojuego, aunque siempre dentro de unos márgenes de actuación concretos: es lo que Víctor Navarro Remesal denomina "libertad dirigida". El autor considera que los videojuegos son "un cibertexto generador de discursos que ofrece posibilidad de acción a jugador pero también se las limita; el diseñador crea una serie de discursos posibles y el jugador ejecuta el cibertexto y genera uno concreto de entre todos los posibles".22 A partir de este diálogo entre el diseñador y el jugador, se crea la partida, el discurso, que se desarrolla en "unos márgenes de acción limitados que crean tanto poder como impotencia, como libertad dirigida". ${ }^{23}$

Para cuantificar hasta qué punto el jugador puede intervenir sobre el videojuego, Navarro Remesal identifica cuatro ámbitos de libertad que se pueden articular en la partida: libertad de movimiento, libertad de resolución para adoptar distintas estrategias cara a resolver los problemas que plantea el sistema, libertad de

tation 4 como en Xbox One (y también, aunque en menor medida, en las consolas de la siguiente generación tanto de Sony como de Microsoft, PlayStation 5 y Xbox Series, respectivamente). Los responsables del estudio polaco pidieron disculpas públicas y la compañía comenzó una revisión contrarreloj para salvar el juego mientras arreciaban las críticas y sus acciones bajaban en bolsa. Solo en los primeros días, la compañía lanzó hasta tres parches para corregir errores, y estimó que el juego será plenamente operativo para febrero de 2021. Sobre esta controversia, véase GONZÁLEZ, Sergio C., “Cyberpunk 2077 en PS4 y Xbox One no estará arreglado hasta febrero de 2021", Meristation, 14 de diciembre de 2020. Versión online: https://as.com/meristation/2020/12/14/noticias/1607933613_701145.html [última consulta: 14-diciembre-2020]- Pese a estas deficiencias, el diseño de la ciudad se puede vislumbrar perfectamente en todas las versiones, por lo que estos problemas de rendimiento, que aún con los primeros parches dificultan sobremanera la jugabilidad, no afectan al presente análisis.

22 NAVARRO REMESAL, Victor, Libertad dirigida. Una gramática del análisis y diseño de videojuegos, Shangrila Textos Aparte, Santander, 2015, p. 311.

23 Ibidem. 
edición para personalizar el contenido y generar contenido propio (incluyendo los editores de niveles), y libertad de ruta para modificar la estructura del juego. ${ }^{24}$ En el caso de Cyberpunk 2077, se alcanza un alto grado de libertad, gracias a su condición de juego de rol que desarrolla mecánicas propias de los sandbox, los shooter en primera persona y los juegos de conducción, en una línea próxima a lo que había supuesto The Elder Scrolls V: Skyrim o la saga Rage, cuya primera entrega salió en 2011 y que combina estos mismos elementos en un mundo postapocalíptico, en la línea de la saga fílmica Mad Max. ${ }^{25}$

La vertiente rolera de Cyberpunk 2077 será la dominante dentro de esta mezcla. El videojuego, de hecho, está basado en un juego de rol de mesa lanzado en los años de efervescencia del subgénero: se trata de Cyberpunk 2020, creado por Mike Pondsmith y que salió al mercado en $1988 .{ }^{26}$ Para reforzar esta orientación, el juego permite elegir entre tres clases (Corpo, Nómada y Netrunner), cada una de ellas con un punto de inicio diferente en la partida y con habilidades y algunas opciones de diálogo diferenciados. Los tres itinerarios convergen en una misma situación de partida tras un prólogo que incluye la primera misión, pero las distintas elecciones del jugador pueden llevarle a una variedad notable de finales. ${ }^{27}$ Así pues, en base a estas variables y a su propia mecánica, Cyberpunk 2077 ofrece al jugador libertad deambulatoria y de ruta, así como distintas opciones para resolver conflictos (asociadas en gran medida a la clase que se elija de partida). En cuando

$24 \quad$ Ibidem, p. 316.

25 El sandbox es un género de videojuegos que se define por desarrollarse en un mundo abierto y por una estructura narrativa no lineal. Minecraft (2009), The Elder Scrolls V: Skyrim (2011), Red Dead Redemption (2013) y su secuela, Red Dead Redemption 2 (2018), Grand Theft Auto V (2013) o The Witcher III: Wild Hunt (2015) son algunos títulos vinculados a este género. En ocasiones, el mundo abierto se combina con mecánicas propias del shooter (juego de disparos) en primera o tercera persona, o de los videojuegos de rol. Sobre géneros de videojuegos y dinámicas jugables, véase NAVARRO REMESAL, Víctor, Libertad dirigida. Una gramática del análisis y diseño de videojuegos, Shangrila Textos Aparte, Santander, 2015; y también NAVARRO REMESAL, Víctor (coord.), Pensar el juego. 25 caminos para los game studies, Shangrila Textos Aparte, Valencia, 2020.

26 Para este análisis se ha manejado la segunda edición en español del juego, lanzada en 1993 por M+D Editores

27 Los análisis del videojuego han identificado hasta seis finales diferentes para Cyberpunk 2077. a la edición, el videojuego permite al jugador crear y modificar sus objetos con una amplia variedad de potenciadores, pero no se incluye ningún editor de niveles ni de escenarios.

En relación al escenario de la acción, la megalópolis distópica, en el juego se percibe con nitidez la influencia tanto de Blade Runner, palpable en las ilustraciones y en la propia atmósfera que destilan los personajes y las situaciones descritas, como de Neuromante, de donde se extrae tanto la conexión cibernética como el propio nombre de la urbe. ${ }^{28}$ En el juego de rol de mesa original, Night City era una ciudad de cinco millones de habitantes situada en la costa californiana, entre Monterrey y San Luis Obispo. El centro financiero se situaba en una manzana circular, preñada de rascacielos, y el resto de la ciudad se organizaba en un plano reticulado. ${ }^{29}$

A la hora de trasladar esta urbe de papel a un entorno gráfico, el equipo de CD Projekt RED recogió toda la fecunda herencia previa de megalópolis distópicas, con Blade Runner como piedra angular de la ambientación. ${ }^{30} \mathrm{Ni}$ ght City se divide en seis distritos, cada uno con una naturaleza propia y definida, que serán a su vez el refugio de comunidades concretas. El centro corporativo es el corazón financiero y empresarial de la urbe, una zona dominada por los grandes rascacielos que ejercen de sede de las corporaciones. Es terreno de los corpos, los empleados de esas compañías, y cuenta además con una gran oferta de ocio, legal e ilegal.

${ }_{28}$ En la novela de Gibson, Night City es un estrecho desarrollo urbano que ha crecido entre la ciudad de Chiba y su puerto. Se trata de una zona sin ley, unos bajos fondos dominados por organizaciones criminales.

29 El plano de la urbe, su historia y una detallada relación de servicios se incluyen en Night City. Guia urbana para Cyberpunk, M+D Editores, Madrid, 1994. El tomo, un apoyo para el volumen principal del juego de rol, está coordinado por el propio Mike Pondsmith y cuenta con ilustraciones de Chris Hockabout y Mike Jackson. El plano es obra de TK Scott.

30 Aunque en un mundo marcadamente colectivo como el del videojuego aún no está plenamente instalada la idea de reconocer la "autoría” (salvo en casos muy concretos como Shigeru Miyamoto o Hideo Kojima), en Cyberpunk 2077 hay una serie de figuras clave que es necesario reseñar. Adam Badowski ejerció como director del juego; en el diseño participaron activamente Konrad Tomaszkiewicz (responsable del título que dio fama al estudio, The Witcher III: Wild Hunt) y el propio Mike Pondsmith. En cuanto al diseño de Night City, el coordinador de entornos de la ciudad es Hiroshi Sakakibara. 
Bordeando el centro corporativo por el sur, como una corona, se localiza Heywood, una zona atravesada por grandes diferencias sociales, en la que se asienta la comunidad latina. $\mathrm{Al}$ sureste se sitúa Santo Domingo, la zona industrial de la urbe. Más al sur está Pacífica, un proyecto de resort turístico fallido dominado por una banda de origen caribeño, los Hijos del Vudú, y poblado por una comunidad criolla.

$\mathrm{Al}$ este del centro corporativo, lindando con él, se sitúa Westbrook, un distrito marcado por las zonas residenciales de las clases altas, pero en el que se localiza también un gran centro de ocio, Japantown. Este subdistrito crea a su vez un cinturón de carácter oriental con Kabuki y Little China, dos enclaves del distrito de Watson. En este cinturón será donde se perciba, de forma más palpable, la herencia de obras como Blade Runner y Akira.

La colisión entre el núcleo financiero del centro corporativo, con sus grandes rascacielos, y la progresiva marginalidad que anega las otras zonas de la urbe denota la profunda brecha social que atraviesa la ciudad. El brutalismo arquitectónico -que emerge puntualmente tanto en la forma de descomunales edificios como en estructuras urbanas, incluyendo unos enormes ventiladores presentes en varias zonas-, refuerza estas diferencias. La publicidad sigue siendo ubicua, hipersexualizada e igual de invasiva, aunque la proliferación de proyecciones de grandes dimensiones remite a experiencias posteriores como Blade Runner 2049 o la serie de televisión Altered Carbon (Laeta Kalogridis, 2018-2020). En el caso de Cyberpunk 2077, estas proyecciones toman la forma de imponentes columnas de luz que se elevan hacia los cielos, integrándose de forma decisiva en el skyline de la urbe, continuamente sobrevolado por una aeronave publicitaria parecida a la que se veía en los primeros minutos de Blade Runner. [Figura 4]

Como indica esa ubicuidad de la publicidad, las corporaciones tienen el control de Night City. Y su forma de mantener el orden es una suerte de estado pseudopolicial, en el que los agentes se presentan con rapidez en cualquier momento y lugar. ${ }^{31}$ Ya en los primeros compases del videojuego se presenta una unidad

Esta ubicuidad de las fuerzas policiales ha sido objeto de controversia entre algunos jugadores, que consideran que la rápida respuesta de los agentes ante una que se descuelga desde un vehículo aéreo, tal y como lo hacían los agentes de Precrimen en Minority Report o el cuerpo de jueces en los cómics de Juez Dredd.

Aunque existen los vehículos voladores, visibles únicamente en el centro de la ciudad, para desplazarse por Night City se utilizarán preferentemente vehículos sobre ruedas. La urbe está interconectada por diversas autopistas y en su trazado se integran amplias avenidas. Como en los cómics de Akira, estas vías rápidas serán objeto de veloces persecuciones, una conexión que se refuerza además por el hecho de que, entre los primeros vehículos puestos a disposición del jugador, se incluye una versión de la icónica moto de Kaneda, denominada Yaiba Kusanagi CT-3X. [Figura 5]

Asimismo, el mundo virtual tendrá una presencia fundamental en la trama de Cyberpunk 2077. Más allá de la propia evolución del personaje, que se puede especializar en los hackeos informáticos reforzando la importancia de su pericia en el ciberespacio, hay dos elementos clave en el juego que refuerzas esta componente virtual. El primero es la figura de Johnny Silverhand, un constructo digital realizado a partir de la personalidad de un rockero (y terrorista) muerto décadas atrás y que, tras serle implantado al protagonista en los primeros compases del juego, irá invadiendo progresivamente su mente, lo que unido a la paulatina sustitución de la anatomía del personaje por piezas biónicas profundiza en la inquietud ante el posthumanismo y el temor a la pérdida del yo presentes en Ghost in the Shell. Incluso se puede presentir esa nostalgia de la reencarnación que postula Aarón Rodríguez Serrano al analizar el filme de Mamoru Oshii. ${ }^{32}$ Silver-

actividad delictiva puede deberse a algún tipo de bug o error de programación.

32 RODRÍGUEZ SERRANO, Aarón, Ghost in the Shell. Nostalgia de la reencarnación, Shangrila Textos Aparte, Santander, 2017. Hay otro filme previo, aunque mucho menos relevante y en cualquier caso posterior al manga de Shirow (publicado originalmente por entregas entre 1989 y 1990) que explora la invasión de una conciencia por parte de otra, tras una infección artificial: se trata de Freejack: Sin identidad (Freejack, Geoff Murphy, 1992), que adapta libremente la novela Immortality, Inc., de Robert Sheckley (1959). Por otro lado, resulta muy revelador el hecho de que, en Cyberpunk 2077, el personaje de Johnny Silverhand esté encarnado por Keanu Reeves, protagonista tanto de Matrix como de Johnny Mnemonic (Robert Long, 


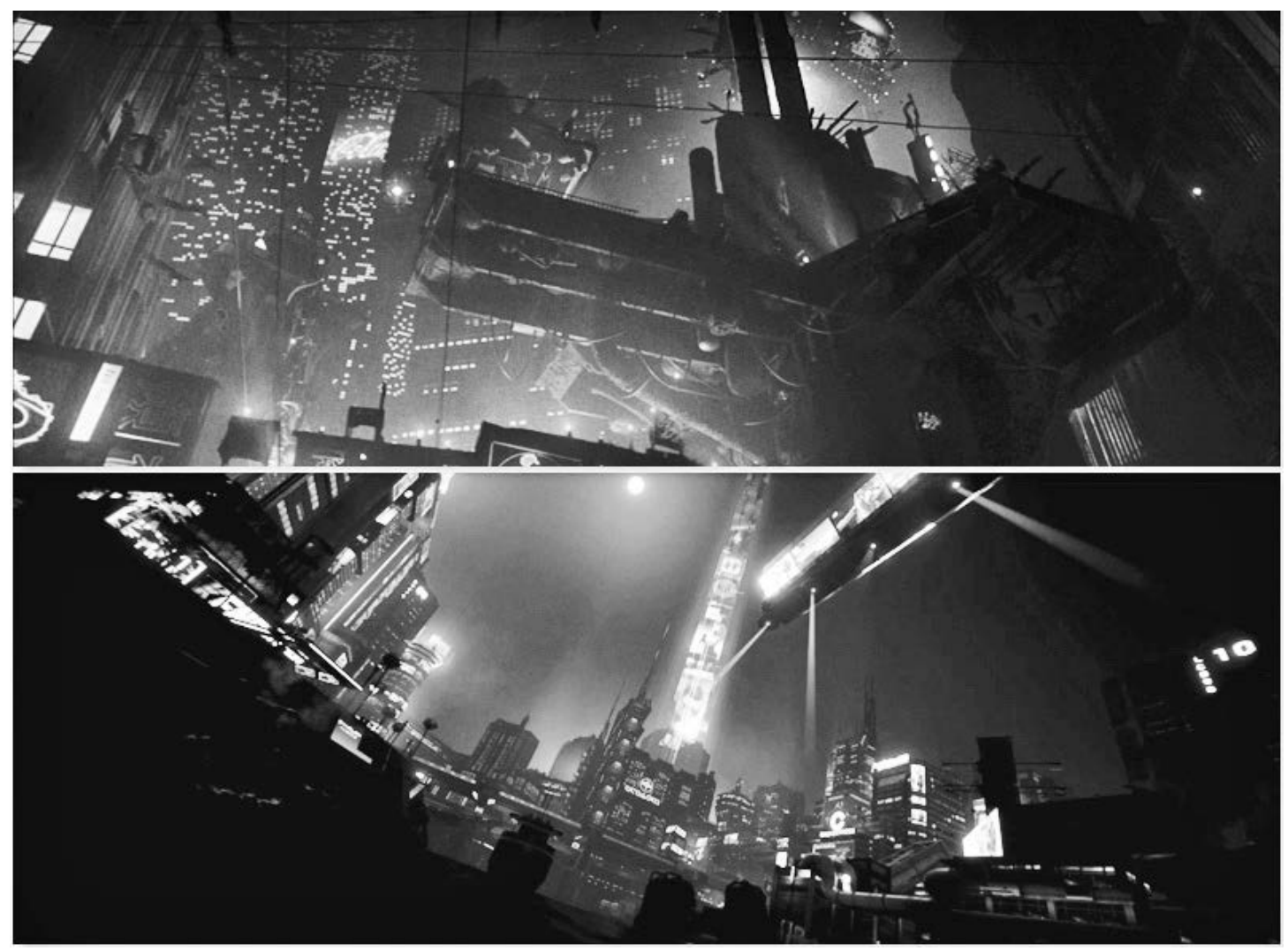

Fig. 4. Arriba, un fotograma de Blade Runner; abajo, una captura in-game de Cyberpunk 2077.

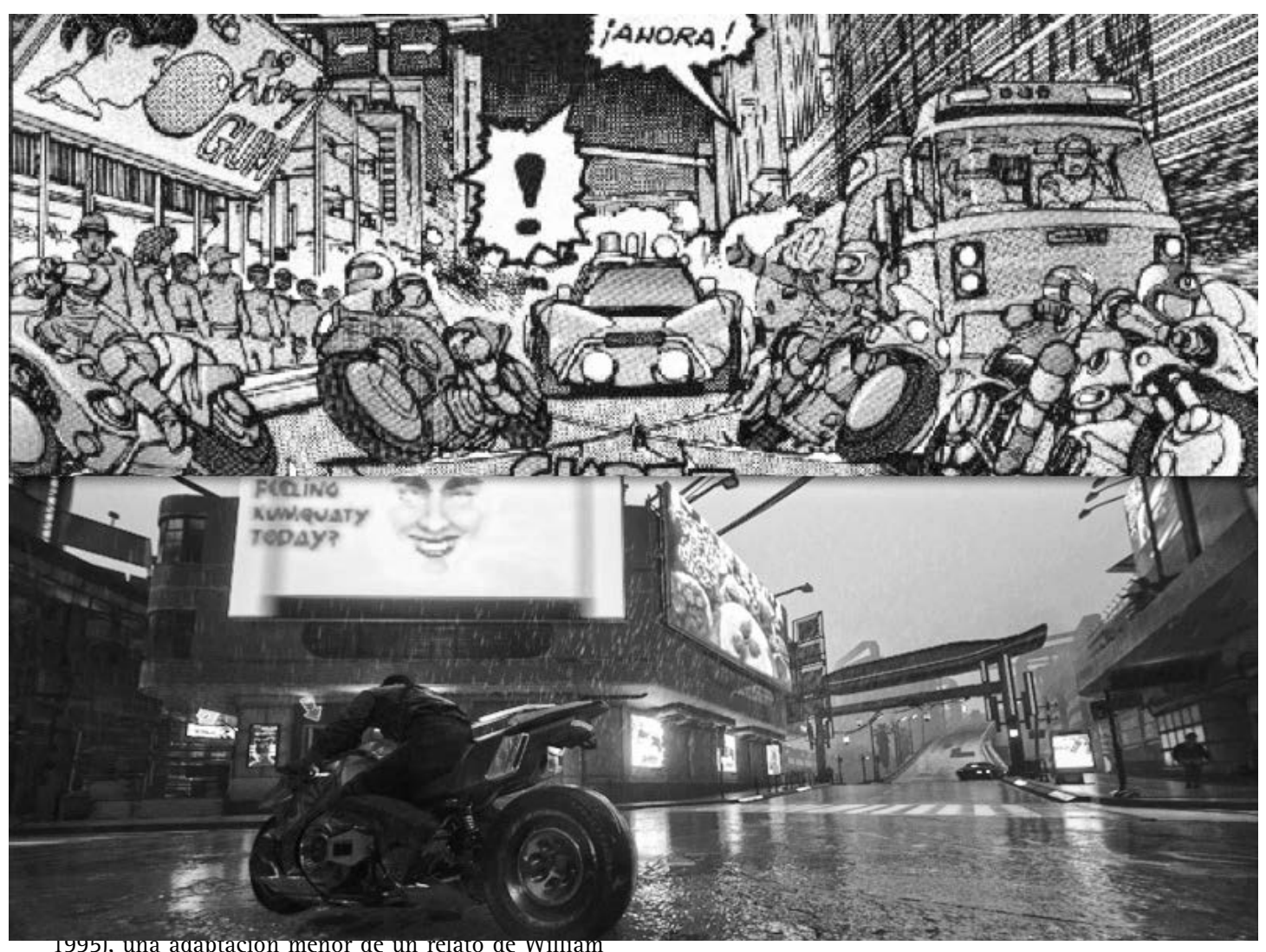

Fig. Gilasciha, una viñeta del tomo 2 del manga Akira; abajo, captura in-game de Cyberpunk 2077. 
hand, en cualquier caso, no deja de ser sino otra materialización del doppelgänger.

Además de la presencia de Silverhand, la otra gran puerta a lo virtual se realiza a través de las llamadas neurodanzas, una grabaciones en primera persona con las que el protagonista puede interactuar, y que le darán pistas para resolver determinados enigmas y avanzar en la historia. Aunque algunos analistas del juego, encargados de reseñarlo en revistas especializadas, han querido ver en estas neurodanzas una reminiscencia del editor de imágenes presente en el primer Blade Runner, ${ }^{33}$ en realidad su naturaleza y su mecánica remiten directamente a Días extraños, toda vez que se trata de grabaciones neuronales que permiten reproducir tanto lo que vio como lo que sintió el autor, y que se pueden reproducir (y en este caso editar) a través de una suerte de corona.

La suma de todos estos elementos, unida a la perspectiva en primera persona que adopta el videojuego y a esa libertad aparente propia de los videojuegos sandbox, propicia una experiencia inmersiva inédita, la sensación de estar realmente viviendo (y muriendo) en una megalópolis distópica. Pero por esta misma herencia asimilada, en nuestras andanzas por Night City, todo tiene un aire familiar. Los distintos ambientes de la urbe replican estructuras análogas a las que proliferan en los cómics de Moebius $o$ en el cine que recrea esos desarrollos urbanos distópicos, y también muchas situaciones, prácticamente todas de hecho, dejan ese poso de familiaridad, de algo ya visto, ya experimentado. Mas no se trata solo de eso.

Night City, en esencia, no es muy distinta de algunas de las grandes ciudades contemporáneas, como pueden ser Tokio, Hong Kong, Nueva York o incluso la deprimida Detroit, cuyo ocaso industrial ha precipitado su decandencia. ${ }^{34}$ De hecho, algunas obras cinematográficas ya perciben la deriva distópica de

33 Cfr. MARTÍNEZ, David, "Análisis Cyberpunk 2077. Uno de los mejores RPG de la generación", Hobbyconsolas, 7 de diciembre de 2020. Dirección web: https:// www.hobbyconsolas.com/reviews/analisis-cyberpunk-2077-mejores-rpg-generacion-767155 [Última consulta: 10-diciembre-2020]. Martínez define las neurodanzas como "un homenaje a la secuencia en que Deckard explora unas imágenes en Blade Runner, pero ejecutadas en $360^{\circ}$ ".

34 Cfr. RODRÍGUEZ, E. J., "Detroit: así se hundió el Titanic del capitalismo estadounidense", Jot Down, febrero de 2013. Versión online: https://www.jotdown. es/2013/02/detroit-asi-se-hundio-el-titanic-del-capi- muchas urbes norteamericanas y japonesas. Black Rain (Ridley Scott, 1989), ambientada en Tokio; Se7en (David Fincher, 1995), en Nueva York; o la propia Matrix, en la que ese mundo virtual diseñado por las máquinas para esclavizar a los humanos se inspira directamente en las grandes ciudades del siglo XX, inciden en esa integración de elementos propios de las distopías cyberpunk en ambientes y tramas contemporáneas. Pero acaso ninguna solución sea tan expresiva como la planteada por Kathryn Bigelow y James Cameron, en su condición de productor y guionista, en Días extraños. En el filme, estrenado en 1995 y ambientado en un futuro cercano, el fin de año de 1999, basta la inclusión de un elemento cyberpunk, el "squid" (un aparato que permite al usuario recrear los recuerdos y las sensaciones de otras personas a través de grabaciones neuronales), para convertir la ciudad contemporánea de Los Ángeles en una megalópolis distópica al borde de una revolución. El asesinato de un cantante y activista de raza negra a manos de la policía, grabado por una prostituta que llevaba conectado el ingenio, precipita un estallido social que puede derivar en una guerra racial.

Aunque la trama bebe de la violencia desatada tras la paliza a Rodney King en 1991, un cuarto de siglo después la película cobra una nueva dimensión tras los enfrentamientos registrados a lo largo y ancho de Estados Unidos tras el asesinato de George Floyd, a manos de agentes de la policía de Mineápolis, el 25 de mayo de 2020, registrada mediante teléfonos móviles y difundida a través de las redes sociales. Las circunstancias que rodean a la muerte de Floyd y las protestas, enmarcadas en plena pandemia de covid-19, se acercan inquietantemente a las plasmadas en Días extraños.

Desde esta perspectiva, la Night City de Cyberpunk 2077 se puede interpretar no solo como una representación decisiva, por su asunción del legado precedente y por su condición interactiva, de la iconografía de las megalópolis distópicas, sino también como un inquietante reflejo, distorsionado pero también estilizado, de las grandes ciudades contemporáneas. Night City se revelaría, así, como parte de la dualidad nuclear en la configuración de las urbes protodistópicas del presente.

talismo-estadounidense/ [Última consulta: 10-diciembre-2020] 